\title{
Reasons and Countermeasures of Plateau Phenomenon in the Development of Backbone PE Teachers in Colleges and Universities
}

\author{
Yaoliang Zhang \\ Zhuhai College of Jilin University \\ 279399748@qq.com
}

Keywords: University backbone PE teachers; Plateau phenomenon; Reasons; Countermeasures

\begin{abstract}
Through the investigation and website search on the related data, as well as the relevant university physical education teachers, the field investigation and the interview were carried on. After that, at the time of deeply comprehending the plateau phenomenon of sports teacher, I also carried out a further investigation on plateau phenomenon occurring in the university backbone sports teacher. Finally the paper makes some reasonable suggestion by analyzing the reason, performance and characteristics of the plateau phenomenon to reduce the plateau phenomenon in the development of backbone PE teachers in colleges and universities.
\end{abstract}

\section{Introduction}

The plateau phenomenon of the backbone PE teachers in the process of growth has the characteristics of universality and regularity. The existence of this plateau phenomenon has a great negative effect on the growth of PE teachers in colleges and universities, because this plateau phenomenon will not only affect the lazy consciousness of PE teachers to make no progress, but also reduce their pursuit of sports knowledge and accomplishment. At the same time, it will lower the overall level of China's college physical education. Therefore, we must attach importance to the plateau phenomenon of college sports teachers in the process of teaching, timely make an adjustment to corresponding countermeasures.

\section{The Definition of the "Plateau Phenomenon" Emerging in the Backbone PE Teachers in Colleges and Universities}

The original meaning of "plateau phenomenon" is that when people rise to a certain altitude, one kind of the natural physiological response appears because of adapting to situations of air pressure dropping, oxygen reduction, little water in air and other issues produced by the rise of altitude. Plateau phenomenon is called that short-term stop or decline appears in the stage of formation of learning or upgrade in educational psychology.

Specific to the plateau phenomenon happening in the growth process of backbone teachers of physical education, it refers to that a situation appears when the backbone teachers rise to a certain position, their professional knowledge and skills in sports aspects declines, the titles stop stagnating and the positions maintain the original situation of the land. This phenomenon is not only a stagnation of career, but also an inevitable result of the decline of the possibility of promotion, and finally it will be an important factor in decline of honor, ability, initiative in the teaching process of the physical education teachers. If this kind of plateau phenomenon cannot get timely adjustment and settlement, it is easy to pull down their own and even the team's academic standards and research capabilities. The harm of this negative impact is enormous; therefore, it is necessary to deal with this plateau phenomenon timely and rationally.

\section{The Characteristics of Plateau Phenomenon of Backbone Teachers in Colleges and} Universities

The Causes of the Appearance of Plateau Phenomena are Diverse. Although the appearance of plateau phenomenon have the characteristics of universality and regularity in the growth of the 
physical education teachers, when the combination of specific schools and physical education teachers, it will show differences in characteristics. This diversity is mainly influenced by three factors. The first is the teacher's own factors. The ideology exists a huge difference in the process of growing for physical education teachers, therein; some PE teachers always maintain a high degree of enthusiasm for learning and exploration and actively enhance their professionalism and comprehensive literacy, using all opportunities of carrying out exploration and learning to enhance their own. While some teachers slowly take things as they are in the seemingly endless teaching career with their thought degenerating slowly. If no conditions or opportunities, they will sit back and relax, while they have the opportunities but not to fight for them because of doubting their ability and self-confidence. The progressive thinking starting at the era of students is easily left to become the stage of physical education teachers. Second are the school environment factors. Whether it is valued for sports or not, or exploiting pioneering and innovative sports teaching mode or relative sports activity valued by the university, have an important influence on the growth of PE teachers. In many colleges and universities, the school puts the key points on the teaching of professional courses. As to the scientific research and academic research and natural research, they focus on key disciplines and professional courses, while the inspection and requirements on physical education and teaching process cannot meet the possible requirements as other professional often. The requirements for students are just to pass the examination in the process of physical education of many colleges and universities, no excessively professional demands are put forward. And the requirements are same to physical education teachers. Make discrimination for professional assessment requirements of physical education teachers with other teachers. At the same time, the sports investment of school for the further expansion and research is not enough, which largely limits the enthusiasm of physical education teachers. The final is social environment factors. For the overall social environment of China is similar to the school environment on the degree of attention to sports. In the community such as work needs, activities, meetings and so on, most of them are other professional. Sports professional needs are often limited to a small part of the sports students or sports enthusiasts. The overall environment further bound the development of physical education; naturally, plateau phenomenon of physical education teachers is more obvious than others.

The Appearance of Plateau Phenomenon Is Inevitable. This inevitability mainly refers to a regularity and universality. A survey showed that $91 \%$ of the physical education teachers in the stage of professional sports will get fall into phenomenon. The reasons for this phenomenon have the similar characteristics with other professional courses, but it also has its own characteristics. The most obvious manifestation of this feature is that it is twist and turns spiral mode in the process of the development of physical education teachers. This is a process from low-level to high-level development. At the initial stage, the teacher's performance will be full of energy and confidence, often put a lot of energy to carry out physical education teaching and research, but also put the practice of sports into reality, the time of this period will be pulled longer. In the growth stage, physical education teacher's energy and ability of exploration will be more or less decline. With the deepening of experience in this period, more professional problems will follow, the decline of their proactive spirit often wear out physical education teacher's patience and confidence, so that they began to slow down the pace or even stagnate in-situ, followed by the stage of plateau phenomenon. In this period, the mental and physical fatigue will make more of the backbone of physical education teachers be content with the status quo, and more in-depth understanding of the current social Sports development environment, which will further reduce the desire to explore the quality of sports and even practice for their own professional knowledge.

The Individual Performance of the Plateau Phenomenon Has Particularity. Everyone in the learning process will have its own characteristics; this phenomenon is manifested in all aspects of society. The teachers in physical education teaching profession are no exception. They have large differences because of the level of ability and their own reasons of individuals in the process of growth in physical education. Their ability to receive new things and attitudes to continually study the practice are different, which will lead to their own efficiency with high or low level in the teaching part. For example, the attitudes of physical education teachers in the course of teaching 
will affect the student's sports class effect, optimistic and positive teachers can drive the passion of each student to learn sports professional knowledge, and thus will enhance their curiosity. While the contented and thought-provoking teachers will be in a psychological status of completing the teaching of physical education. The final result is that the relationship is alienated between teachers and students, reducing the teacher's enthusiasm.

\section{Causes of the Appearance of Plateau Phenomenon}

The Immediate Factor Is the Emergence of Non-Linear Professional Development Model. In general, the development process of teacher industry can be classified as a similar process, that is to say, from the initial stage to the growth stage, then to the plateau stage, then to the overcoming stage and finally to the rapid development stage. This non-linear process in the growth stage of the performance of physical education teachers is very obvious. They receive a large number of professional knowledge in the stage of students, and enhance their own sports accomplishment and ability of sports practice. This kind of comprehensive development lays a solid foundation for them to become a physical education teacher in the future. But the replacement of knowledge and the gap more or less between professional knowledge and the actual textbooks will make more physical education teachers just feel powerless, especially in the teaching session, the environment and the requirements of this kind of teaching mode have a big difference compared with student learning period. It is not very easy to grasp them when combining professional knowledge and practical teaching. At this time, the confidence of sports teachers will be set back inevitably. At the same time, forming a set of knowledge structure and ability system suitable for them cannot be easily achieved, therefore, all of that will have a big negative impact on the development of teacher's comprehensive quality and the motivation of exploring and learning professional knowledge.

The Objective Factor Is the Environment of Physical Education Teaching. This kind of objective reasons is divided into the itself marginalization of curriculum, the teaching content as well as the teacher oneself factor. The itself marginalization of the curriculum mainly talks that the whole position of physical education is not like other professional courses in the school, the recognition degree of the school is not enough, resulting that the students don't care the results of the learning process, and the teachers will naturally reduce detection desire and curiosity because of the overall teaching environment. Many colleges and universities lack the corresponding rules and regulations to make overall assessment and requirements from all aspects on the physical education teacher. For sports teacher, this kind of environment greatly reduces the awareness of competition, intellectual and entrepreneurial. As to teaching content, sports teaching content requirements show the phenomenon and the requirements are lower, different from other professional knowledge that the mandatory requirements are carried out for academic research and scientific research results.. Sports teaching often value test results of students, it will be enough for students to get the ideal results to pass the examination smoothly or ensure that most of the students have achieved the requirements of the credit points. Therefore, more physical education teachers will only stay the requirements of the school with the public physical education curriculum ability, lacking the competition awareness of further exploring professional knowledge of sports. The most direct manifestation of teachers' own factors is the stability of PE teaching and the strained predicament of personal development opportunities. Some teachers will stagnate and become complacent after the teaching level has reached the requirements of the school. Although some teachers are conscious of the competition, the limitation of the teaching environment has restricted the teachers' psychology of inquiry learning. The lack of development opportunities lead to a much lower level of physical education directly.

The Social Reasons for the Emergence of Physical Education Is Facing Social Pressures. With the popularization of higher education and the promotion of teachers' academic requirements, undergraduates have lost their advantages in the competition of teaching posts. A large number of postgraduates and even doctoral students have begun to compete for the positions of PE teachers. The pressure of competition has brought a direct threat to the position, title and their own interests of the original teachers. Coupled with the difficulties of social employment, especially the high 
standards of quality for the teachers industry, which lead to the unprecedented competition in physical education teachers. More schools select outstanding sports teacher through the layers of strict examination and interviews, Compared with the previous teachers, they will have the advantage in the ability, adapting to the environment, creativity and so on, which increased the pressure on the existing physical education teachers invisibly, resulting in self-confidence of a lot of sports teachers were suppressed. Some teachers will appear negative psychology, so the plateau phenomenon in the growth is inevitable.

The Subjective Reason of the Emergence for Physical Education Teachers Is the Difference between Their Own Attitude and Literacy. The styles for everyone who treat the same job is bound to be different, and the sports teacher industry has no exception. The differences of teachers' attitude and literacy produce a big difference when they look at their work. For teachers who care about salary and treatment, their requirements for work are low, only need to keep a living job which can meet their life. This kind of mental quality directly led to their work with the status quo or muddle. As the position of sports where the physical and mental are equally important, which are naturally different from other professional teaching, but the reality is the school and community do not treated them differently, developing a unified assessment criteria for assessment, which undoubtedly reduced the enthusiasm of teachers. It will be more likely to breed negatively psychological progress. For a long time, the plateau phenomenon will only elongate and always continue.

\section{The Strategies to Solve the Plateau Phenomenon}

Improve the Environment and Create an Enabling Environment. Adjusting the overall status of PE Teaching in Teaching. Schools and the community should further emphasize the important position of sports teaching of the students in the learning process. The high development of today's society asks larger demands for students' comprehensive literacy. As an important component of comprehensive literacy, sport no doubt needs to gain the attention of students, teachers, schools and even society. It is very important to optimize the PE teaching environment by incorporating PE into one of the necessary evaluation criteria. At the same time the physical education teacher also should be provided with as much as possible learning, training opportunities, so that they are ready to learn and further enhance their own comprehensive literacy. This is also an important factor in cultivating self-confidence. Finally, improve and perfect the evaluation system of physical education curriculum. Combined with the particularity of PE teaching, perfect the link of the evaluation, adjust the index of literacy, professional and ability according to the characteristics of physical education curriculum, so as to adapt the PE teaching process to the greatest extent.

Focus on Physical Education Teacher's Team Building and Enhance the Quality of the Group. Modernization of the national education model requires that the sports teacher of school should improve their own in all aspects. Building a harmonious team of teachers is particularly important. Therefore, it is necessary to strengthen the team building of outstanding PE teachers and strengthen the harmonious and enterprising spirit among teachers through team building. Tap out the effectiveness of the team think tank, develop teachers and learning resources, but also promote the exchange of experience and skills between teachers to expand the strong side of the team, at the same time, they can effectively prevent the emergence of negative lazy psychology of individual teachers. In this appropriate teaching atmosphere of competition, their talent and enthusiasm in various aspects are fully mobilized. While we also should pay attention to improving the teachers' professional theoretical accomplishment and ability through team building. We should combine the strong ability of the teachers with high qualifications with the existing teachers. In the meantime, we should also advocate the teachers with lower ability to get a further advanced education. Through training and learning, and ultimately the overall level of physical education teachers can be improved.

Enhance the Awareness of the Self-Evaluation Reflection of Teachers and Improve Their Quality. For the plateau phenomenon happening in college sports teacher, a greatly subjective factor is the existence of negative lazy emotion in the teachers. The lack of motivation to make a 
progress, so it is necessary to establish a system of specific operational evaluation mechanism to enhance teachers' own assessment on self-consciousness and enthusiasm. This reflection and evaluation standards should be comprehensive multi-directional, positive, reverse and the combination of quantitative and qualitative, horizontal and vertical and so on, to carry out multi-angle reflection evaluation. It is necessary to pay attention to their own evaluation, but also they actively listen to the judgment of others to them. If there is a mistake, change it and if not, be on the alert. The ultimate goal is to upgrade their own professionalism and overall quality totally.

Tailored to Self-Development Plan and Confirm a Clear Goal. In the course of the development of teachers' career, it is very important to formulate feasible development goals on a regular basis. Professional requirements of each stage are different, and the goal of each stage should also be adjusted accordingly. At the same time, according to their hobbies, strengths and weaknesses, as well as the requirements of professional, PE teachers should confirm a development planning for tailored. In their own development process, they need to pay attention to combine the standards and requirements of the school with their own actual situation of organically, and fully tap their own potential so as to overcome the plateau phenomenon. Besides, they should improve the initiative, make sure their clear direction and objectives of development, avoid falling into the unnecessary dilemma, and improve the possibility of the success of their own professional development.

\section{Conclusion}

In the development of backbone PE teachers in colleges and universities, the plateau phenomenon is a big obstacle and the factor of restricting further promotion. Therefore, no matter that teachers or schools should attach great importance to this question. We can formulate the regulations of development methods appropriately, and provide external space conditions for sports teachers to successfully overcome plateau phenomenon. To provide an enabling environment for their long-term development and even the development of China's sports professional. At the same time, teachers should also enhance their own professionalism, and give way to their own potential and enthusiasm through effective means of mining, to avoid the bottleneck in the development of obstacles. Through setting out the long-term development goals for regular review of reflection, we can raise this kind of consciousness to the height of personality. In the information age, the idea of "Never too old to learn" is advocated and applied to the teachers. Establish lifelong pursuit of learning objectives, and do one's efforts to their own continuous development.

\section{References}

[1] Qian Bing, Zheng You. Causes and countermeasures of "Plateau Phenomenon" in Teachers' Professional Development. School-based Training Network, 2006 (08).

[2] Chen Xiange. Analysis and recommendations on the career plateau phenomenon in medium-term of career. Human Resource Development, 2006 (6).

[3] Li Chunhui. The "plateau phenomenon" and countermeasures on professional development of PE teachers in Colleges and universities. Journal of Chengdu Sport University, 2011 (07).

[4] Li Liying, Liu Yanfang. The factors and countermeasures of plateau phenomenon in the Growth of Backbone PE Teachers in Colleges and Universities. Sports World, 2016 (10).

[5] Xue Liucheng. The construction of inquiry - based PE teaching model. Sports Culture Guide, 2003 (01): 12-14. 